\title{
STRATEGI PENGEMBANGAN KOMPETENSI UNTUK MENINGKATKAN KINERJA TENAGA KEPENDIDIKAN PADA BAGIAN AKADEMIK DI UNIVERSITAS TRUNOJOYO MADURA
}

\author{
Intan Pratiwi \\ Magister Managemen, Universitas Trunojoyo Madura \\ Intanirsyad76@gmail.com
}

\begin{abstract}
Abstrak: Penelitian ini dimaksudkan untuk merumuskan Pengembangan Kompetensi Untuk meningkatkan Tenaga Kependidikan pada Bagian Akademik di Universitas Trunojoyo Madura yang meliputi: kompetensi berkaitan dengan kinerja tenaga kependidikan dan stategi atau upaya meningkatkan kompetensi tenaga kependidikan untuk meningkatkan kinerja. Penelitian ini menggunakan metode kualitatif. Data dikumpulkan menggunakan observasi, wawancara, dan dokumentasi. Dari hasil penelitian didapat hasil bahwa kompetensi yang dimiliki dapat meningkatkan kinerja tenaga kependidikan pada bagian akademik di Universitas Trunojoyo Madura, meskipun ada beberapa hal yang perlu terus dikembangkan. Dan strategi pengembangan kompetensi tenaga kependidikan di Universitas Trunojoyo Madura dapat dilakukan melalui pendidikan dan pelatihan. Pelatihan dilakukan dengan dua pendekatan yakni pendekatan off the job training dan pendekatan on the job training.
\end{abstract}

Kata Kunci: strategi; pengembangan; kompetensi; tenaga kependidikan

\begin{abstract}
This research is intended to formulate Competency Development to improve the teaching staff in the Academic Section at the University of Trunojoyo Madura which includes: competencies related to the performance of educational staff and strategies or efforts to improve the competence of teaching staff to improve performance. This study uses a qualitative method. Data collected using observation, interviews, and documentation. The results of the research show that the competencies possessed can improve the performance of the teaching staff in the academic section of the University of Trunojoyo, Madura, although there are a number of things that need to be developed. And the strategy of developing the competency of education staff at the University of Trunojoyo Madura can be done through education and training. The training is carried out with two approaches namely the off the job training approach and the on the job training approach.
\end{abstract}

Kata Kunci: strategi; pengembangan; kompetensi; tenaga kependidikan 


\section{PENDAHULUAN}

Sumber daya manusia merupakan salah satu faktor yang paling penting dan paling menentukan dalam setiap organisasi. Saat ini, dengan begitu pesatnya perkembangan teknologi yang semakin canggih, maka setiap individu dituntut untuk dapat menggali segala sumber daya manusia yang dimiliki, agar dapat menunjang kinerja yang nantinya akan sangat berpengaruh pada pelaksanaan tugas setiap hari. Bahkan sistem sarana dan prasarana dalam organisasi dapat terus berkembang dan terus disempurnakan seiring berjalannya waktu, sehingga suatu organisasi dapat berkembang sesuai dengan sumber daya manusia yang ada. Banyak para ahli berpendapat bahwa sumber daya manusia yang berkualitas sangat menentukan berhasil atau tidaknya suatu organisasi dengan kompetensi dari setiap pegawai yang ada. Dan untuk membentuk sumber daya manusia yang berkualitas tersebut memerlukan waktu dan proses yang lama serta upaya yang dilakukan secara terusmenerus.

Universitas Trunojoyo Madura merupakan Universitas negeri satu-satunya di pulau Madura. Awal mula berdiri dengan nama Universitas Bangkalan (Unibang), baru kemudian di tahun 2001 Unibang di negerikan dan berganti nama Universitas Trunojoyo Madura. Saat ini Universitas Trunojoyo Madura memiliki tujuh fakultas dan 37 program studi. Salah satu penunjang pelayanannya adalah di bidang Akademik yang dijalankan oleh tenaga kependidikan.

Pada penelitian kali ini akan diteliti apakah kompetensi yang dimikliki dapat meningkatkan kinerja tenaga kependidikan pada bagian akademik Universitas Trunojoyo Madura, dan strategi pengembangan kompetensi seperti apa yang diperlukan untuk meningkatkan kinerja tenaga kependidikan bagian akademik Universitas Trunojoyo Madura.

\section{METODE PENELITIAN}

Penelitian ini menggunakan metode penelitian kualitatif, yang menekankan pada kedalaman hasil penelitian dimana peneliti sendiri terlibat langsung sebagai instrumen penelitian. Metode kualitatif merupakan suatu penelitian kontekstual yang menjadikan manusia sebagai instrumen, dan disesuaikan dengan situasi yang wajar dalam kaitannya dengan pengumpulan data yang pada umumnya bersifat kualitatif. Menurut (Moleong, 2001) menyatakan bahwa "kualitatif merupakan prosedur meneliti yang menghasilkan data deskriptif berupa kata-kata tertulis atau lisan dari orangorang dan perilaku yang dapat diamati".

Menurut (Ardianto, 2010) menjelaskan bahwa "penelitian kualitatif merupakan perilaku artistik. Pendekatan filosofis dan aplikasi metode dalam kerangka penelitian kualitatif dimaksudkan untuk memproduksi "ilmu-ilmu lunak" seperti: sosiologi, antropologi, (komunikasi dan publik relations, Pen) peneliti kualitatif percaya bahwa "kebenaran" (Truth) adalah dinamis dan dapat ditemukan hanya melalui penelaan terhadap orang-orang dalam interaksinya dengan situasi sosial kesejatahan (Danim, 2002)." Subjek dalam penelitian ini adalah Tenaga Kependidikan pada Bagian 
Akademik Universitas Trunojoyo Madura yang berjumlah keseluruhannya 22 orang tetapi yang menjadi subjek penelitian hanya 7 orang saja.

Penelitian ini akan mengkaji tentang Strategi Pengembangan Kompetensi Untuk Meningkatkan Kinerja Tenaga Kependidikan pada Bagian Akademik Universitas Trunojoyo Madura, dan yang menjadi subjek penelitian kali ini adalah pegawai pada Bagian Akademik. Untuk itu diperlukan ada penetapan Informan dalam penelitian ini.

Menurut (Simatupang, 2017) Informan terdiri dari dua yakni informan pangkal dan informan pokok (key informan). Informan pangkal adalah orang yang dipandang mampu memberikan informasi secara umum dan mampu menunjuk orang lain sebagai informan pokok yang dapat memberikan informasi yang lebih mendalam. Informan Pangkal dalam penelitian ini adalah Kepala Biro Umum dan Keuangan Universitas Trunojoyo Madura (Informan 1), yang dianggap mampu memberikan informasi selanjutnya juga bisa memberikan rekomendasi siapa-siapa saja yang bisa dijadikan informan pokok dalam penelitian ini. Untuk Informan Pokok dalam penelitian ini adalah enam kepala tata usaha dan 1 kepala subbagian umum di tujuh Universitas Trunojoyo Madura yang ditetapkan sebanyak 7 orang informan.

Pengumpulan data dilakukan menggunakan metode wawancara mendalam (in-depth interview) dan observasi. Wawancara merupakan alat pembuktian terhadap informasi atau sebagai keterangan yang diperoleh sebelumnya. Wawancara mendalam (in-depth interview) adalah proses memperoleh keterangan untuk tujuan penelitian dengan cara tanya jawab sambil bertatap muka antara pewawancara dengan informan atau orang yang diwawancarai, dengan atau tanpa menggunakan pedoman (guide) wawancara, dimana pewawancara dan informan terlibat dalam kehidupan sosial yang relatif lama (Hidayat \& Sutopo, 2006).

Menurut (Moleong, 2001) menyatakan bahwa "sumber data utama dalam penelitian kualitatif adalah kata-kata dan tindakan sebagai data primer, selebihnya adalah data tambahan. Artinya, kata-kata dan tindakan dari subjek hanyalah sebuah catatan (informasi) yang tidaklah memberikan arti apapun sebelum dikategorisasikan dan direduksi. Jadi kemampuan peneliti adalah menangkap data, bukan sekedar mencerna informasi verbal tetapi mampu pula mengungkap dibalik tindakan atau bahasa nonverbal responden."

Menurut (Pristiyono, 2015) berpendapat bahwa “Observasi merupakan teknik pengumpulan data, dimana peneliti melakukan pengamatan secara langsung ke objek penelitian untuk melihat dari dekat kegiatan yang dilakukan." 


\section{HASIL PENELITIAN DAN PEMBAHASAN}

Tenaga Kependidikan di Universitas Trunojoyo Madura terdiri dari kepala biro, kepala tata usaha, kepala subbagian, staf bagian administrasi (keuangan, akademik, kemahasiswaan, kepegawaian dan umum), laboran, pustakawan dan pranata komputer.

Dari tujuh fakultas dan 36 program studi yang ada di Universitas Trunojoyo Madura terdapat 12 orang tenaga kependidikan yang berstatus Pegawai Negeri Sipil (PNS) dan 22 tenaga kependidikan yang berstatus non PNS yang menangani bidang akademik.

Status pendidikan dari tenaga kependidikan PNS rata-rata adalah Strata 1 (S1) begitu juga dengan tenaga kependidikan non PNS. Selebihnya adalah lulusan Diploma 3 (D3) baik tenaga kependidikan PNS maupun yang non PNS.

Dilihat dari segi komptensi yang dimiliki oleh tenaga kependidikan pada bagian akademik Universitas Trunojoyo Madura sudah lumayan bagus. Hal ini dapat dibuktikan berdasarkan penilaian pimpinan (kepala tata usaha) terhadap kompetensi tenaga kependidikan bagian akademik di tujuh fakultas melalui teknik wawancara.

Dari hasil wawancara tersebut dapat dikatakan bahwa kompetensi tenaga kependidikan pada bagian akademik bisa dikatakan cukup baik dari sisi profesionalisme yakni yang terkait dengan pelaksanaan pekerjaan rutinnya, menguasai pekerjaan yang menjadi tugas pokok sehari-hari (tupoksi) beserta persoalan-persoalan yang muncul akibat pekerjaannya dapat diselesaikan dengan baik. Hal ini berdasarkan pendapat dari X1 yang menyatakan bahwa "tendik disini kompetensinya cukup bagus, mereka menguasi pekerjaan dan segala macam persoalan yang muncul dalam pekerjaannya dapat mereka selesaikan". Pendapat X2 juga menyatakan bahwa "tenaga kependidikan di fakultasnya memiliki kompetensi yang lumayan bagus, namun perlu dikembangkan lebih lanjut". Begitu juga dengan pendapat yang lain menyatakan bahwa kompetensi cukup bagus.

Untuk kompetensi umum yakni yang berkaitan pilihan pribadi untuk memilih melaksanakan kewajiban sebagai suami atau istri pada saat jam kerja ada. Namun dari sisi kompetensi sosial masih perlu dibenahi karena masih ada beberapa Tenaga kependidikan yang kurang baik pelayanannya terhadap mahasiswa maupun dosen. Hal ini didasarkan pada pendapat X4, dan X6 yang menyatakan masih ada mahasiswa dan dosen yang merasa pelayanan tenaga kependidikan kurang, baik dari segi komunikasi maupun kecepatan pelayanan.

Dengan mengacu pada berbagai uraian tentang kinerja dan penilian dari atasan langsungnya yakni kepala subbagian akademik, maka kinerja tenaga kependidikan bagian akademik Universitas Trunojoyo Madura dapat dikatakan cukup bagus, berdasarkan pendapat dari X7 yang menyatakan "Kinerja tendik bagus bisa dilihat dari nilai PPK mereka, meski ada beberapa yang perlu ditingkatkan lagi". Begitu juga pendapat kepala Tata usaha dari fakultas yang lain.

Kinerja dikatakan baik didasarkan pada bukti Penilaian Prestasi Kerja (PPK) dari masing-masing tenaga kependidikan bagian akademik menunjukkan angka rata-rata 85 keatas. Hasil PPK inilah yang menunjukkan tercapai atau tidaknya kinerja dari setiap Apatatur Sipil Negara, dan khusus tendik hasil dari PPK ini berkaitan erat dengan tunjangan kinerja yang akan diperoleh. 
Disamping penilaian atas kinerja yang telah dicapai, dinilai juga atas orientasi pelayanan, komitmen, integritas, loyalitas, kedisiplinan dan kepemimpinan bagi setiap Aparatur Sipil Negara. Dan penilaiannya jadi satu kesatuan dengan PPK.

Dengan demikian dapat disimpulkan bahwa kompetensi yang dimiliki dapat meningkatkan kinerja tenaga kependidikan pada bagian akademik di Universitas Trunojoyo Madura, meskipun ada beberapa hal yang nantinya perlu terus dikembangkan.

Pengembangan kompetensi memerlukan strategi agar benar-benar mencapai hasil sebagaimana yang diharapkan. Dan strategi pengembangan kompetensi yang dapat digunakan untuk pengembangan kompetensi Tenaga Kependidikan pada Bagian Akademik di Universitas Trunojoyo Madura adalah dengan pelatihan dan pendidikan.

Pelatihan untuk pengembangan kompetensi tenaga kependidikan pada bagian akademik di Univeristas Trunojoyo Madura dapat dilakukan melalui dua pendekatan yaitu pendekatan off the job training dan on the job training. Untuk pelatihan dengan pendekatan off the job training yakni dengan mengirimkan tenaga kependidikan pada bagian akademik mengikuti diklat, workshop, prajab ataupun diklatpim.

Kondisi saat ini, Tenaga Kependidikan pada bagian akademik secara keseluruhan sudah mengikuti prajab bagi yang masih staf, sedangkan untuk kepala subbagian masih ada beberapa yang belum mengikuti diklat kepemimpinan (Diklatpim). Karena penyelenggaraan diklatpim dan prajab tepusat pada kementerian otomastis bersifat pasif menunggu adanya kuota dari kementerian.

Dalam hal mengirimkan tenaga kependidikan pada bagian akademik untuk mengikuti workshop atau pelatihan-pelatihan di luar tempat kerja belum pernah ada bagi tenaga kependidikan pada bagian akademik di level fakultas. Padahal pelatihan atau workshop tersebut sangat dibutuhkan oleh tenaga kependidikan pada bagian akademik di Universitas Trunojoyo Madura. Hal ini dibuktikan dengan minimnya sertifikat keikutsertaan pelatihan dan workshop dari tenaga kependidikan pada bagian akademik. Padahal untuk pengembangan akreditasi universitas pengembangan kompetensi yang dibuktikan dengan sertifikat tersebut sangat besar kontribusinya.

Untuk itu, ada baiknya pihak universitas untuk dapat mengikutsertakan tenaga kependidikan pada bagian akademik mengikuti pelatihan-pelatihan atau workshop di luar Universitas, dengan cara mengalokasikan sebagian anggaran untuk mengikutsertakan tenaga kependidikan mengikuti workshop dan pelatihan tersebut untuk pengembangan kompetensinya, baik kompetensi dirinya maupun kompetensi bagi organisasi atau universitas.

Sedangkan pelatihan dengan pendekatan on the job training yaitu pelatihan dilakukan didalam lingkungan kerja. Meski kompetensi yang dimiliki oleh tenaga kependidikan pada bagian akademik cukup bagus, namum kemampuan mereka perlu ditingkatkan melalui pelatihan-pelatihan yang nantinya dapat mensupport pekerjaannya. Namun, pelatihan-pelatihan yang diselenggarakan oleh internal kampus masih kurang. Sehingga, ada beberapa pimpinan yang juga menginginkan adanya pelatihan dengan metode ini bagi straf-stafnya. Misalnya pelatihan public speaking, pelayanan prima dan lain-lain yang memang sangat dibutuhkan oleh tenaga kependidikan pada bagian 
akademik, dimana tugas mereka adalah dibagian pelayanan yang selalu berinteraksi dengan mahasiswa dan dosen.

Begitu juga pelatihan IT, sangat diharapkan untuk dapat mengembangkan kompetensi tenaga kependidikan pada bagian akademik, mengingat latar belakang pendidikan para tenaga kependidikan pada bagian akademik tidak semuanya dari teknik, akan tetap pekerjaan yang mereka lakukan setiap hari selalu memanfaatkan IT. Setiap saat mereka harus mengolah data akademik yang perlu disajikan pada pimpinan terkait dengan perkembangan akademik mahasiswa, namun sistem akademik tidak mampu menyajikan data tersebut. Sehingga terkadang penyajian informasi yang diperlukan oleh pimpinan tidak dapat terlaksana secara efektif dan efisien. Untuk kebutuhan-kebutuhan pelatihan yang diuraikan diatas seyogyanya dapat dilakukan secara mandiri baik di tingkat Fakultas maupun tingkat universitas. Fakultas atau Universitas mestinya mengalokasian anggaran untuk mengadakan pelatihan-pelatihan yang dilakukan di dalam kampus.

Terakhir terkait dengan pendidikan tenaga kependidikan pada bagian akademik di Universitas Trunojoyo Madura. Kondisi saat ini pendidikan tenaga akademik sebagian besar adalah Strata 1 (S1) menyusul berikutnya Diploma 3 (D3) dan satu orang berpendidikan SMA. Tingkat pendidikan tenaga kependidikan pada bagian akademik ini masih perlu ditingkatkan lagi. Meskipun masih ada diantara tenaga kependidikan pada bagian bagian akademik ini merasa enggan tidak melanjutkan studi karena tidak adanya biaya untuk melanjutkan studi. Meski sebagian besar ada juga tenaga kependidikan pada bagian akademik yang melanjutkan studi dengan biaya sendiri, dengan harapan dapat meningkatkan kompetensi dan karirnya.

Masih ada beberapa tenaga kependidikan pada bagian akademik Universitas Trunojoyo Madura kurang berminat untuk melanjutkan pendidikannya ke jenjang strata 1 (S1) bagi yang masih berpendidikan Diploma, dan melanjutkan ke jenjang strata 2 (S2) bagi yang berpendidikan S1. Faktor biaya, usia, tidak ada waktu luang untuk kuliah, kemampuan untuk belajar sudah tidak mampu lagi, dan juga tidak lama lagi memasuki masa persiapan pensiun menjadi alasan untuk tidak melanjutkan studi ke jenjang yang lebih tinggi.

Alasan-alasan seperti diatas tidak akan mampu menghantarkan seseorang lebih berkembang, baik untuk peningkatan karir maupun untuk meningkatkan kinerjanya. Beberapa aspek yang harus dilakukan untuk mewujudkan kompetensi, yaitu dengan cara kerja keras dan ada keinginan yang besar untuk mau belajar dan terus belajar tanpa memikirkan hal-hal yang membatasi kita untuk mundur dan tidak ingin berkembang, sebab ilmu pengetahuan dan keterampilan yang dimiliki akan membawa pemiliknya pada sebuah kesuksesan.

Melanjutkan studi bagi tenaga kependidikan sangat besar manfaatnya selain untuk pengembangan kompetensi diri juga dapat meningkatkan kinerja universitas yang dinilai dari akreditasi dari universitas itu sendiri. Semakin banyak tenaga pendidik (dosen) dan tenaga kependidikan yang melanjutkan studi, maka akan menambah poin penilaian akreditasi.

Selama ini beasiswa studi lanjut untuk tenaga kependidikan tidak pernah ada, hal ini berbeda dengan tenaga pendidik(dosen) yang banyak mendapat beasiswa ketika 
melaksanakan studi lanjut. Untuk itu, perlu kiranya universitas memiliki program pemberian beasiswa atau mendorong tenaga kependidikan untuk melanjutkan studi dengan mendapatkan beasiswa.

\section{KESIMPULAN}

Berdasarkan hasil penelitian tentang strategi pengembangan kompetensi untuk meningkatkan kinerja tenaga kependidikan pada bagian akademik di Universitas Trunojoyo Madura dapat ditarik kesimpulan yakni:

1. Dengan demikian dapat disimpulkan bahwa kompetensi yang dimiliki dapat meningkatkan kinerja tenaga kependidikan pada bagian akademik di Universitas Trunojoyo Madura, meskipun ada beberapa hal yang perlu terus dikembangkan.

2. Strategi pengembangan kompetensi tenaga kependidikan di Universitas Trunojoyo Madura dapat dilakukan melalui pendidikan dan pelatihan. Pelatihan dapat dilakukan dengan dua pendekatan yakni pendekatan off the job training dan pendekatan on the job training.

\section{SARAN}

Penelitian yang dilakukan diharapkan hasil dari penelitian bisa diterapkan dengan tujuan Penelitian ini dimaksudkan untuk merumuskan Pengembangan Kompetensi Untuk meningkatkan.

\section{UCAPAN TERIMAKASIH}

Ucapan terima kasih penulis sampaikan kepada seluruh narasumber yang bersedia membantu dan memberikan informasi yang diperlukan pada penelitian ini. Ucapan terima kasih juga kami sampaikan kepada para pihak yang membantu dalam selesainya tulisan ini.

\section{REFERENSI}

Ardianto, E. (2010). Metode Penelitian Untuk Public Relatios Kuantitatif Dan Kualitatif. Simbiosa Rekatama Media.

Amstrong, Michael. 1994. Performance Management. Kogan Page Limited.

Drucker, Peter, M. 2001. People And Performance. Wobun: Butterworth Heneimann

Danim, S. (2002). Menjadi peneliti kualitatif. Bandung: pustaka setia.

Fatmawada, S, 2016, Pengembagan Kompetensi Tenaga Kependidikan di Universitas Negeri Makasar : Jurnal Office Vol.2, No.2.

Hidayat, N., \& Sutopo, A. (2006). Peranan interpreter dalam pengembangan usaha ekspor industri rotan.

Moleong, L. J. (2001). Metode Penelitian Kualitatif, cetakan keempatbelas. Bandung: PT Remaja Rosdakarya (Anggota IKAPI). 
Palan, R. (2007) Competency Management: Teknis Mengimplementasikan Manajemen SDM Berbasis Kompetensi untuk Meningkatkan Daya Saing Organisasi.PPM. Jakarta.

PP. No. 19 Tahun 2005, Standar Pendidikan dan Tenaga Kependidikan

Pristiyono, P. (2015). Pengaruh Proses Pemberian Kredit Terhadap Minat Nasabah Pada Pt Bank Mandiri (Persero) Tbkkantor Cabang Komplek Tasbi Medan. Ecobisma (Jurnal Ekonomi, Bisnis Dan Manajemen), 2(2), 84-92.

Schuler, Randall S, Susan E Jakson. 1997. Manajemen Sumber Daya Manusia: Menghadapi Abad Ke 21. Erlangga. Jakarta.

Spencer dan Spencer. 1993. Competence at Work:Models for Superrior Performance, John Wily \& Son,Inc,New York,USA.

Sule, Ernie Tisnawati and Saefullah. 2009.Pengantar Manajemen Kencana Prenada Media Group. Jakarta.

Suparno, Paul.,2005. Miskonsepsi dan Perubahan Konsep dalam Pendidikan Fisika, PT. Gramedia Widia Sarana, Yogyakarta.

Simatupang, M. (2017). Gambaran Keharmonisan Commuter Family Pada Anggota Brigade Mobile Kepolisian Daerah Sumatera Utara. Analitika: Jurnal Magister Psikologi UMA, 9(1), 27-35.

Undang-undang Nomor 2, Tahun 1989,Tentang Sistem Pendidikan Nasional

Wibowo, 2007, Manajemen Kinerja, Jakarta : Raja Grafindo Persada. 